\title{
A rotational drum fermentation system with water flushing for enhancing hydrolysis and acidification of solid organic wastes
} Jing Gan ${ }^{\mathrm{a}}$, Ling Chen ${ }^{\mathrm{a}}$, Baoming $\mathrm{Li}^{\mathrm{a}}$, Weizhong Jiang ${ }^{\mathrm{a}^{*}}$, Yutaka Kitamura ${ }^{\mathrm{b}}$

\author{
${ }^{a}$ Key Lab of Agricultural Bioenvironment Engineering, Ministry of Agriculture, P. R. China, \\ China Agricultural University, Beijing, 100083, China \\ ${ }^{\mathrm{b}}$ Graduate School of Life \& Environmental Sciences, University of Tsukuba, Japan 305-8572 \\ ${ }^{*}$ Corresponding Author. Tel.: 86-10-62737992; Fax: 86-10-62736413 \\ E-mail address: jiangwz@cau.edu.cn
}

\begin{abstract}
In this work, fresh soybean meal was used as the substrate for both batch and continuous experiments in a rotational drum fermentation (RDF) system to characterize the acidogenic process of solid organic waste degradation at high unionized volatile acid (U-VA) level and evaluate the effect of water flushing on the acidogenic performance. The experiments were conducted under mesophilic condition with a reaction time of 20 days. The results of the batch experiment showed that U-VA had a growing adverse effect on the volatile acid (VA) production and hydrolysis of the substrate as the initially added U-VA concentration increased $(0,5,15,25 \mathrm{~g} / \mathrm{L})$. VA formation deteriorated drastically when the initial U-VA
\end{abstract}


concentration exceeded $5 \mathrm{~g} / \mathrm{L}$. VS degradation ratios decreased from $43.8 \%$ to $7.3 \%$, and the hydrolysis rate constants varied between 28.8 and $3.8 \times 10^{-3} / \mathrm{d}$ in response to the initial U-VA concentration. In the continuous experiment, two Cascade process configurations (CP1 and CP2) without and with VA removal by water flushing, respectively, were developed. The results showed that the hydrolysis rate constants and VS degradation ratios were $13.1 \times 10^{-3} / \mathrm{d}$ and 23\%, respectively, in CP2, while only $9.1 \times 10^{-3} / \mathrm{d}$ and $16.7 \%$ in CP2. Compared to CP1, the VA spectrum varied little in CP2 with water flushing. It suggested that the higher U-VA level had a significant inhibition on the acidogenic process of solid organic waste degradation, and the VA removal by water flushing improved the acidogenic performance.

Keywords: unionized volatile acid, water flushing, volatile solid degradation ratio, hydrolysis rate constant, rotational drum fermentation system 


\section{Introduction}

Anaerobic degradation of solid organic waste is an excellent alternative to dumping, composting, landfill, incinerating and simple fermentation processes, from the viewpoint of both energy conversion and environment conservation. The process of anaerobic degradation process is normally considered involving three phases, i.e., hydrolysis/acidogenesis, acetogenesis, and methanogenesis. In comparison with the conventional one-phase process, the multiple-phase process could improve the anaerobic digestion performance (Azbar et al., 2001). Especially, the two-phase anaerobic digestion composed of acidogenic and methanogenic processes has been widely used in treating industrial wastewater (Bull et al., 1984), dairy-industry wastes (Ghosh et al., 1994; Demirer and Chen, 2005), and municipal solid wastes (Ghosh et al., 1995; Bouallagui et al., 2005).

As a preliminary step of the two-phase anaerobic degradation, the acidogenic process produces not only substrates for methane generation but also industry materials such as volatile acids and ethanol. With the aim to enhance the hydrolysis and obtain the maximum VA yield, the acidogenic process has being attracted more attentions in recent years. The hydrolysis is the rate-limiting step when the substrate is highly complex or cellulose-rich, such as solid waste (Eastman et al., 1981). The rate of hydrolysis is a function of the factors including $\mathrm{pH}$, temperature, components and particle size (available surface) of the substrate, process or reactor configurations, and the intermediate products (Veeken et al., 1999). 
Some investigations about the effect of the intermediate products on the acidogenesis were conducted. According to the degradation model proposed by Veeken and his co-workers (2000), the accumulation of the metabolic intermediary products such as VA may hinder not only the methanogenesis but also the hydrolysis and the acidogenesis. It was found that VA concentration was one of the most important parameters in anaerobic degradation (Ahring et al., 1994). Ten Brummeler and his co-workers (1991) observed that a VA concentration of 33 g/L would lead to a severe inhibition to hydrolysis of biowaste. Veeken et al. (2000) found that the hydrolysis of biowaste was completely inhibited under VA levels up to 40-50 $\mathrm{g}$ VA-COD/L.

Some researchers regarded the unionized volatile acid (U-VA) as the inhibitor contributing to VA inhibition (Anderson et al., 1982; Baronofsky et al., 1984; Garcia et al., 1991; Wang and Wang, 1984). The U-VA concentration is a function of $\mathrm{pH}$ and $\mathrm{pK}_{\mathrm{a}}$, and it increases with the decrease of pH (Palmqvist et al., 2000). Therefore U-VA inhibition can be recognized as the restraint from both low $\mathrm{pH}$ and VA accumulation on substrate hydrolysis. It was suspected that the hydrolysis rate of solid organic particles was affected by U-VA (Llabres-Luengo et al., 1988). In addition, U-VA was also unfavorable for methanogenesis, which was inhibited when U-VA was greater than $60 \mathrm{mg} / \mathrm{l}$ (Kroeker et al., 1979).

To obtain the maximum VA yield and accelerate the degradation of solid organic waste, Jiang and his co-workers (2005) developed a solid recycle process of the rotational drum 
fermentation (RDF) system with leachate recirculation from the methanogenic to the acidogenic processes. The results showed that the leachate recirculation and the separation of hydrolysis from acidogenesis improved the acidogenic performance. Nevertheless, the phenomena of products inhibition were still observed. To buffer the adverse influence of U-VA on the acidogenic process, it is necessary to characterize the acidogenic process of solid organic waste degradation at high U-VA levels.

The objectives of this work were to (1) evaluate the effects of U-VA on acidogenic performance by a batch experiment; (2) develop a Cascade process of the RDF system with VA removal by water flushing to buffer the U-VA inhibition and assist the hydrolysis and acidification in anaerobic solid organic waste degradation.

\section{Methods}

\subsection{Substrates and inoculum}

Fresh soybean meal (approximately $17.1 \%$ total solid) from a dining hall of China Agriculture University (Beijing, China) was used as the substrates. The dry soybean meal was composed of protein (22.5\%), fat (19.1\%), sugar (37.7\%), fiber (14.6\%) and ash (6.1\%) as analyzed by Han et al.(2004).

The inoculum to fermenters was the anaerobic digestion sludge from a municipal wastewater treatment plant (Beijing, China). 


\subsection{Experimental apparatus}

A RDF system developed by Jiang and his co-workers (2005) was used. It consisted of four fermenters named I, II, III, and IV. The fermenters (3.6L) were all filled with aluminum oxide milling balls (diameter: $30 \mathrm{~mm}$ ) that took $10 \%$ volume. This system was operated in an incubator under a constant mesophilic temperature $\left(35 \pm 1^{\circ} \mathrm{C}\right)$. Rotation was conducted for 15 minutes at 30-minute intervals at a speed of $12 \mathrm{rpm}$ throughout the entire experimental period.

\subsection{Batch experiment to study the effect of U-VA on acidogenesis}

In order to evaluate the effect of U-VA on the acidogenic performance at various U-VA levels, pure acetic acid was chosen to simulate the products of acidogenic process to add in the fermenters initially, because of its dominance in solid-state waste anaerobic biodegradation by the RDF system (Jiang et al., 2002).

In each fermenter, the weight ratio of the fresh soybean meal to the sludge was $1: 1$. The pure acetic acid added into the fermenter after the mixture of feedstock and seed sludge was loaded ranged from 0 to $30 \mathrm{~g} / \mathrm{L}$ with the increment of $10 \mathrm{~g} / \mathrm{L}$. The initial $\mathrm{pH}$ of each fermenter decreased from 7.6 to 4.1, and the initial U-VA levels were 0 , 5, 15 and 25 g/L, respectively. The nitrogen was injected into the fermenters to maintaining the anaerobic condition.

The batch fermentation lasted for 20 days. All parameters were determined at the termination of the batch fermentation.

2.4. Effect of water flushing on acidogenesis by continuous experiment 


\subsubsection{Cascade process configurations}

The cascade process configurations were shown in Fig. 1. Cascade process 1 (CP1) consisted of fermenters I and II. Soybean meal was fed to fermenter I, whose effluent was fed to fermenter II as feedstock without losing hydrolytic and acidogenic microorganisms. Finally, the sludge from fermenter II was discharged as an effluent of CP1.

Fermenters III and IV constituted Cascade process 2 (CP2). The effluent of fermenter III was flushed with $50 \mathrm{~g}$ deionized water. Then the same amount liquid was separated by a juice presser (Pearl Metal Co. Ltd., HBJCT) with a 25-mesh sieve (SUS316). The residue was then fed into fermenter IV. The sludge from fermenter IV was drained as an effluent of CP2.

Fermenters I and III were run under the same condition to ensure their effluent was homogeneous.

\section{Fig. 1 Process configuration of continuous experiment}

\subsubsection{Experimental procedure}

Prior to starting the experiments, fermenters I and III were inoculated with a mixture of the anaerobic sludge and the substrate at a weight ratio of 1:1. Then, the nitrogen was passed through the fermenters to maintain the anaerobic condition. After 20-day acclimation, the feeding of fresh soybean meal was conducted daily by drawing and filling at a 10-day 
hydrolytic retention time (HRT) in fermenters I and III. Fermenters II and IV were started in approximately 20-day acclimation operation after fermenters I and III were fed continuously for 10 days. When fermenters I and III reached the steady state, their daily effluent was fed into fermenters II and IV, respectively. Controlling parameters for the continuous experiment were presented in Table 1.

Samples were taken daily to monitor $\mathrm{pH}$ throughout the experiment. Total solid (TS), VA, and volatile solid (VS) were determined once a week during the unsteady-state period and twice a week during the steady-state period. At the end of experiment, the VA spectrums of fermented sludge were monitored.

\section{Table 1}

2.5. Measurement and analysis

The values of $\mathrm{pH}$, TS, VA, and VS were determined according to the sewage test procedure (Japan Sewage Association, 1997). The samples withdrawn were centrifuged at $3000 \mathrm{rpm}$ for $5 \mathrm{~min}$, and the supernatants were passed through a $0.45 \mu_{\mathrm{m}}$ membrane filter for the analysis of VA spectrum. The VA spectrum was measured using an ion chromatograph (DX600, DIONEX) with an electrochemical detector (ED50).

2.6. Parameters calculation for acidogenic process of anaerobic solid waste degradation 


\subsubsection{VA increasing ratio}

The VA production performance is evaluated by VA increasing ratio which is determined using Equation (1) and (2).

$$
\begin{aligned}
& T V A=(F V A-I V A)+P V A \\
& R_{V A}=T V A / I V A
\end{aligned}
$$

where TVA ( $\mathrm{g}$ ) is the total amount of VA produced in the fermenter; FVA ( $\mathrm{g}$ ) is the final visible VA in the fermenter; IVA (g) is the initial amount of VA added to the fermenter; PVA (g) is the amount of VA converted into final products by methane-producing microbes. $\mathrm{R}_{\mathrm{VA}}$ is the VA increasing ratio.

\subsubsection{U-VA concentration}

It is known that VA exists in solution in two principal forms, i.e., U-VA and ionized VA (I-VA), and the concentration of the former can be calculated using the following equation (Bujoczek et al., 2000).

$$
U V A=V A\left(10^{\left(p K_{a}-p H\right)}\right) /\left(1+10^{\left(p K_{a}-p H\right)}\right)
$$

where $\mathrm{pK}_{\mathrm{a}}$ is the dissociation constant of the acids in water; $\mathrm{pK}_{\mathrm{a}}=4.762$ for acetic acid at $35^{\circ} \mathrm{C}$ (Weast, 1981).

\subsubsection{Hydrolysis rate constant}

Based on the first-order hydrolysis kinetics, the hydrolysis phase can be expressed by the following equation. 


$$
\frac{d S}{d t}=-K_{h} S
$$

where $\mathrm{K}_{\mathrm{h}}(/ \mathrm{d})$ is the hydrolysis rate constant of the particulate matter in fermenters I, II, III and $\mathrm{IV}$, when $\mathrm{h}=1,2,3$, and 4, respectively; $\mathrm{S}$ (g-VS/L) is the substrate concentration in the solid phase.

Based on Equation (4), the hydrolysis rate constant with time can be written as follows:

$$
K_{h}=\frac{1}{T} \ln \left(\frac{S_{0}}{S_{T}}\right)
$$

where $S_{0}(g-V S / L)$ is the initial substrate concentration at $T=0 ; S_{T}(g-V S / L)$ is the substrate concentration in the fermenter withdrawn at time T; T (d) is the reaction time or HRT.

Apparent hydrolysis rate constants ( $\mathrm{K}$ and $\mathrm{K}$ ) for the two cascade processes are deduced by Equation (6) and (7).

$$
K=\frac{1}{T}\left(K_{1} T_{1}+K_{2} T_{2}\right)
$$

where $\mathrm{K}(/ \mathrm{d})$ is the apparent hydrolysis rate constant for CP1; T (d) is the apparent HRT for CP1; $K_{1}$ and $K_{2}(/ d)$ are the hydrolysis rate constants for fermenters I and II, respectively; $T_{1}$, $\mathrm{T}_{2}$ (d) are the HRTs for fermenters I and II, respectively.

$$
K^{\prime}=\frac{1}{T^{\prime}}\left(K_{3} T_{3}+K_{4} T_{4}\right)
$$

where $\mathrm{K}^{\prime}(/ \mathrm{d})$ is the apparent hydrolysis rate constant for CP2; T' (d) is the apparent HRT for $\mathrm{CP} 2 ; \mathrm{K}_{3}$ and $\mathrm{K}_{4}(/ \mathrm{d})$ are the hydrolysis rate constants for fermenters III and IV, respectively; $\mathrm{T}_{3}$ and $\mathrm{T}_{4}(\mathrm{~d})$ are the HRTs for fermenters III and IV, respectively.

\subsubsection{VS degradation ratio}


The VS degradation ratio can be written as follows:

$$
R_{h}=\frac{S_{\text {in }}-S_{\text {out }}}{S_{\text {in }}} \times 100
$$

where $\mathrm{R}_{\mathrm{h}}(\%)$ is the VS degradation ratio in fermenters I, II, III and IV, when $\mathrm{h}=1,2,3$, and 4 , respectively; $S_{\text {in }}\left(\mathrm{g}-\mathrm{VS} / \mathrm{L}\right.$ ) is the initial substrate concentration; $S_{\text {out }}$ (g-VS/L) is the concentration of the substrate withdrawn from fermenters.

The apparent VS degradation ratios of the two cascade processes can be determined by Equation (9) and (10).

$$
R=R_{1}+R_{2}-R_{1} R_{2}
$$

where $\mathrm{R}(\%)$ is the apparent VS degradation ratio for $C P 1 ; \mathrm{R}_{1}$ and $\mathrm{R}_{2}(\%)$ are the VS degradation ratios for fermenters I and II, respectively.

$$
R^{\prime}=R_{3}+R_{4}-R_{3} R_{4}
$$

where $\mathrm{R}^{\prime}(\%)$ is the apparent VS degradation ratio for the CP2; $\mathrm{R}_{3}$ and $\mathrm{R}_{4}(\%)$ are the VS degradation ratios for fermenters III and IV, respectively.

\section{Results and Discussion}

3.1. Effect of U-VA on acidogenesis in batch experiment

\subsubsection{VA production}

The final values of $\mathrm{pH}$, TVA, VA increasing ratios, I-VA and U-VA distributions, U-VA and VA spectrums in the fermenters were shown in Table 2. 
The $\mathrm{pH}$ levels ranged from 4.2 to 5.1 which indicated that the acidogenesis was prevailing in all fermenters. Compared to fermenter $\mathrm{I}$, the $\mathrm{pH}$ in other fermenters decreased with the increase of acetic acid.

The final TVA concentrations at U-VA addition of 0, 5, 15, 25 g/L were 17.3, 14.3, 20, 25.7 g/L, respectively. The VA concentration in fermenter I was higher than that in fermenter II with $10 \mathrm{~g} / \mathrm{L}$ acetic acid addition, while the $\mathrm{pH}$ in fermenter I was greater than fermenter II. The higher VA concentrations and lower $\mathrm{pH}$ levels observed in fermenters III and IV were due to acetic acid addition. It appeared that a more favorable environment for microorganisms was attained in fermenter I without acid addition. Taking the initial VA concentrations into account, the VA increasing ratios in fermenters I, II, III and IV were 33.6, 0.4, 0, and 0, respectively. It was clear that there was an inhibition at high U-VA level which had been reported to relate with $\mathrm{pH}$ and the U-VA was the inhibitor (Anderson et al., 1982). When the initial U-VA level exceeded $5 \mathrm{~g} / \mathrm{L}$, an obvious inhibition was observed as indicated by almost no further VA production. This inhibitory U-VA level was much higher than that reported by Babel et al. (2004) who found that a value of $2.3 \mathrm{~g} / \mathrm{L} \mathrm{U}-\mathrm{VA}$ at $\mathrm{pH} 5$ was responsible for the inhibition of solid waste acidification in an anaerobic acid digestion.

With the increased acetic acid load, there was a decrease in $\mathrm{pH}$ level and a corresponding increase in both U-VA occupying ratio and U-VA concentration. The U-VA was deleterious to the microorganisms and its inhibition on the activity of catabolic enzyme increased with the 
concentration of the inhibitor (Siegert et al., 2005). That was because the U-VA was liposoluble and could diffuse across the plasma membrane, resulting in the acidification of the cytoplasm. Meanwhile, the I-VA with a high level was retained in the culture and increased the ionic strength in solution, leading to cell lysis (Palmqvist et al., 2000; Zheng et al., 2005).

\section{Table 2}

The VA spectrums varied with the acetic acid addition. In fermenter I, acetic acid level was higher, followed by propionic acid and formic acid, whereas no malic acid was detectable. The highest propionic acid content in fermenter I would be fatal for methanogenesis. Acetic acid was more predominant in fermenters II, III and IV due to the acetic acid addition. Compared to fermenter I, succinic acid level increased while formic and propionic acid levels decreased in fermenter II. The propionic acid which was degraded from succinic acid was not detectable in fermenters III and IV. It indicated that long-chain VA such as succinic acid was not conducive to degrade at a higher U-VA concentration.

\subsubsection{Hydrolysis rate constant and VS degradation ratio}

Substituting the experimental data into equations (5) and (8), hydrolysis rate constants and VS degradation ratios of all fermenters were calculated. The hydrolysis rate constants obtained in fermenters I, II, III and IV were $28.8,13.7$, 3.8 and $3.8 \times 10^{-3} / \mathrm{d}$, respectively. The 
corresponding VS degradation ratios were 43.8\%, 24\%, 7.3\%, and 7.3\%, respectively. The $\mathrm{K}_{\mathrm{h}}$ and $\mathrm{R}_{\mathrm{h}}$ in fermenter I were approximately twice of that in fermenter II which shown that the degradation of substrate was inhibited evidently in fermenter II. The lowest $K_{h}$ and $R_{h}$ were occurred in both fermenters III and IV. It implied that the degradation by microorganisms was inhibited significantly. The hydrolysis of the substrate in fermenters III and IV was owing to the shear forces produced by the milling balls. The rotation of the drum compelled the milling balls to fall down from the top and strike against the interior surface of the drum, accompanied with colliding with each other. The shear forces produced accordingly lead the substrates to pulverization. The phenomena indicated that the accumulation of VA may contribute to reduce the hydrolysis rate of the solid organic substrate (Banks and Wang, 1999), or even to inhibition at extremely high level (>10g/L) (Palmisano et al., 1971).

\subsection{Effect of water flushing on acidogenesis in continuous experiment}

The results of the batch experiment revealed that at a lower U-VA level, the fermenter had a tendency to produce more VA than that at a higher one. And the excess U-VA accumulation, in particular $5 \mathrm{~g} / \mathrm{L}$ in this study, had an apparent inhibition on VA production and hydrolysis of the substrate. This inhibition could probably be reduced if the $\mathrm{pH}$ and VA concentration were balanced to an appropriated level, which was lower than the inhibitory level of U-VA (Babel et al., 2004). Some attempts, such as in situ VA removal (Sun et al., 1999; Aljundi et al., 2005; Hirata et al., 2005) and alternation of process configuration (Argelier et al., 1998; Chen et al., 
2006; Jiang et al., 2005), had been made to ease the inhibition. In this work, a method of water flushing was employed to buffer the high-level U-VA inhibition and its effect on acidogenesis was evaluated by a cascade process of RDF system.

The average values of $\mathrm{pH}$, TVA, VA increasing ratios, VA distributions and VA spectrums for all fermenters under the steady-state condition were presented in Table 3. The VS, VS gradients, VS degradation ratios and hydrolysis rate constants were shown in Table 4.

\subsubsection{VA production}

The $\mathrm{pH}$ levels ranged from 5.0 to 5.4 in all fermenters. The same results were obtained in fermenters I and III. Compared to fermenter II, the pH in fermenter IV increased due to water flushing. The VA concentrations in fermenters I, II, III and IV were 8.1, 11.2, 8.1 and $12.2 \mathrm{~g} / \mathrm{L}$, respectively. The cascade process was favorable to establish the gradients of $\mathrm{pH}$ and VA concentration and improved the acidogenic performance (Argelier et al., 1998). The pH value decreased from 6.3 to 5.4 in fermenters I and III, from 5.4 to 5.0 in fermenter II and from 5.4 to 5.1 in fermenter IV. Simultaneously, the VA concentration increased from 0 to $8.1 \mathrm{~g} / \mathrm{L}$ in fermenters I and III, from 8.1 to $11.2 \mathrm{~g} / \mathrm{L}$ in fermenter II and from 5.3 (after water flushing) to 12.2 $\mathrm{g} / \mathrm{L}$ in fermenter IV. The VA increasing ratio in fermenter IV (1.3) was threefold of that in fermenter II (0.4). The greater change of VA concentration and higher VA increasing ratio in fermenter IV was due to the water flushing lowered VA concentration from 8.1 to $5.3 \mathrm{~g} / \mathrm{L}$ and provided a more favorable condition for microorganisms, and enhanced acidogenesis. 
This phenomenon was agreement with the results of the batch experiment that U-VA had an inhibition on acidogenesis. Fermenter I (8.1 g/L) and fermenter II (3.1 g/L) contributed 72.3\% and $27.7 \%$ VA to CP1, respectively. Fermenter III $(8.1 \mathrm{~g} / \mathrm{L})$ and IV $(6.9 \mathrm{~g} / \mathrm{L})$ provided 54\% and $46 \%$ VA for CP2, respectively. Water flushing originated a higher contribution ratio in fermenter IV than that in fermenter II. In terms of VA generation, CP2 with water flushing was more favorable than CP1.

As shown in Table 3, the occupying ratios of U-VA increased as $\mathrm{pH}$ decreased. The highest ratio of U-VA was obtained in fermenter II (34.5\% TVA), followed by fermenter IV (31.6\% TVA), whereas the lowest one occurred in fermenters I and III (17.3 \% TVA). The occupying ratios of U-VA in CP2 were descended through VA removal by water flushing.

The acetic acid was predominant in all fermenters, followed by propionic acid and succinic acid, while formic acid was the lowest one. The VA spectrums varied little in the two processes which indicated that water flushing had little effect on VA spectrum.

Table 3

3.2.2. Hydrolysis rate constant and VS degradation ratio

The hydrolysis rate constants of fermenters I, II, III and IV were 7.9, 10.2, 7.9 and 18.2 $\times 10^{-3} / \mathrm{d}$, respectively. The corresponding VS degradation ratios were $7.6 \%, 9.8 \%, 7.6 \%$, and 
16.7\%, respectively. The $K_{h}$ and $R_{h}$ in fermenter IV were much higher than that in fermenter II. These were because the water flushing diluted the feedstock to fermenter IV and developed the reactants concentration gradient, hence buffered U-VA inhibition and enhanced the degradation.

Substituting $\mathrm{T}=\mathrm{T}_{1}+\mathrm{T}_{2}$ and $\mathrm{T}^{\prime}=\mathrm{T}_{3}+\mathrm{T}_{4}$ to Equation (6), (7), (9) and (10), a $\mathrm{K}$ of $9.1 \times 10^{-3} / \mathrm{d}$, $\mathrm{R}$ of $16.7 \%$ for $\mathrm{CP} 1$ and $\mathrm{K}^{\prime}$ of $13.1 \times 10^{-3} / \mathrm{d}$, R' of $23.0 \%$ for $\mathrm{CP} 2$ were attained, respectively. The hydrolysis rate constant and VS degradation ratio in CP2 were raised remarkably in response to U-VA levels descent by water flushing. It implied that water flushing buffered the U-VA inhibition, promoted the hydrolysis and upgraded the rheological property of the substrate in fermenter IV. Consequently, the intensity of pulverization was elevated and the degradation of the solid particles was accelerated. It indicated that the cascade process using RDF system with water flushing assisted to promote the degradation of solid organic waste.

\section{Table 4}

\section{Conclusions}

Combining the VA production with the VS degradation ratios and hydrolysis rate constants in the batch experiment, it revealed that the extreme U-VA may severely deteriorate the acidogenic process. When U-VA level reached to $5 \mathrm{~g} / \mathrm{L}$, the acidogenic process was inhibited 
obviously. It was necessary to remove the excess U-VA to improve the acidogenic performance of anaerobic solid waste degradation. The water flushing was beneficial to buffer the U-VA inhibition, and improve the acidogenic performance of organic solid-state wastes. The apparatus with optimal parameters for water flushing should be developed in further work.

\section{Acknowledgements}

This research was supported by Special Items Fund of Beijing Municipal Commission of Education (Grant number: XK100190441). The authors gratefully acknowledge the help of Tao Zhou for fabricating the experimental apparatus used in the present investigation.

\section{References}

Ahring, B. K., Sandberg, M., Angelidaki, I., 1994. Volatile fatty acid as indicators of process imblance in anaerobic digesters. Applied Microbiology and Biotechnology 43, 559-565.

Aljundi, I.H., Belovich, J.M., Talu, O., 2005. Adsorption of lactic acid from fermentation broth and aqueous solutions on Zeolite molecular sieves. Chemical Engineering Science 60, 5004-5009.

Anderson, G. K., Donnelly, T., Mckeown, K. J., 1982. Identification and control of inhibition in the anaerobic treatment of industrial wastewater. Process Biochemistry 17(4), 28-32. 
Argelier, S., Delgenes, J. -Ph., Moletta, R., 1998. Design of acidogenic reactors for the anaerobic treatment of the organic fraction of solid food waste. Bioprocess Engineering 18, 309-315.

Azbar, N., Ursillo, P., Speece R. E., 2001. Effect of process configuration and substrate complexity on the performance of anaerobic processes. Water Research 35(3), 817-829.

Babel, S., Fukushi, K., Sitanrassamee, B., 2004. Effect of acid speciation on solid waste liquefaction in an anaerobic acid digester. Water Research 38, 2417-2423.

Banks, C. J., Wang, Z., 1999. Development of a two phase anaerobic digester for the treatment of mixed abbatoir wastes. Water Science Technology 40(1), 69-76.

Baronofsky, J. J., Schreurs, W. J. A., Kashket, E., R., 1984. Uncoupling by acetic acid limits growth of and acetogenesis by Clostridium thermoaceticum. Applied Environmental Microbiology 48 (6), 1134-1139.

Bouallagui, H., Touhami, Y., Cheikh, R. B., Hamdi, M., 2005. Bioreactor performance in anaerobic digestion of fruit and vegetable wastes. Process Biochemistry 40, 989-995.

Bujoczek, G., Oleszkiewicz, J., Sparling, R., Cenkowski, S., 2000. High solid anaerobic digestion of chicken manure. Journal of Agricultural Engineering Research 76, 51-60.

Bull, M. A., Steritt, R. M., Lester J. N., 1984. An evaluation of single- and separated-phase anaerobic industrial wastewater treatment in fluidized bed reactors. Biotechnology and Bioengineering 26, 1054-1065. 
Chen, L., Jiang, W. Z., Kitamura, Y., Li, B. Enhancement of hydrolysis and acidification of solid organic waste by a rotational drum fermentation system with methanogenic leachate recirculation. Bioresource Technology (2006), doi: 10.1016/j.biortech. 2006.08.015.

Demirer, G. N., Chen, S., 2005. Two-phase anaerobic digestion of unscreened dairy manure. Process Biochemistry 40, 3542-3549.

Eastman, J. A., Ferguson, J. F., 1981. Solubilization of particulate organic carbon during the acid phase of anaerobic digestion. Journal of Water Pollution Control Federation 53 (3), 352-365.

Garcia, J. B., Ibanez, R. G., Hani A. Al Ghawas, Sandall, O. C., 1991. On the effect of basicity on the kinetics of $\mathrm{CO}_{2}$ absorption in tertiary amines. Chemical Engineering Science 46 (11), 2927-2931.

Ghosh, S., Fukushi, K., Liu, T., Kalra, S., Mariger, C., Hansen, C., Debirk, L., Christensen, S. S., Millar R., 1994. Pilot plant for biometyhanation of dairy-industry wastes. Bio-energy 94, Proceedings of the Sixth National Bioenergy Conference, Reno/Sparks, Nevada.

Ghosh, S., Buoy, K., Dressell, L., Millar, T., Wilcox, G., Loos, D., 1995. Pilot- and full-scale two-phase anaerobic digestion of municipal sludge. Water Environment Research 67(2), 206-214.

Han, T., Lin, L., Zhang, S., 2004. Soluble fiber food--Exploitation and utilization of soybean meal. Food Research and Development 25 (4), 116-117. 
Hirata, M., Gao, M., Toorisaka, E., Takanashi, H., Hano, T., 2005. Production of lactic acid by continuous electrodialysis fermentation with a glucose concentration controller. Biochemical Engineering Journal 25, 159-163.

Japan Sewage Association. 1997. pH measurement, 110-111; Total Solid and Volatile Solid measurement, 296-297; Volatile Acids measurement, 300-304; Sewage Test Procedure, Japan Sewage Association, Tokyo.

Jiang, W. Z., Kitamura,Y., Ishizuka, N., Shiina, T., 2002. A rotational drum fermentation system (RDFS) for dry methane fermentation (2) ---Effect of hydraulic retention time (HRT) and stirring meida in fermentor on acidogenic process. The Journal of the Society of Agricultural Structures 33 (3), 35-42.

Jiang, W.Z., Kitamura, Y., Li, B., 2005. Improving acidogenic performance in anaerobic degradation of solid organic waste using a rotational drum fermentation system. Bioresource Technology 96, 1537-1543.

Kroeker, E. J., Schulte, D. D., Sparling, A. B., Lapp, H. M., 1979. Anaerobic treatment process stability. Journal of Water Pollution Control Federation 51(4), 718-727.

Llabres-Luengo, P., Mata-Alvarez, J., 1988. The hydrolytic step in a dry digestion system. Biological Wastes 23, 25-37.

Palmisano, A. C., Barlaz, M. A., 1971. Microbiology of solid waste. In :Vreeland RH, Editor. The microbiology of extreme and unusual environments. CRC Press Inc., London, 
p.72-104.

Palmqvist, E., Hahn-Hägerdal, B., 2000. Fermentation of lignocellulosic hydrolysates. II: inhibitors and mechanisms of inhibition. Bioresource Technology 74, 25-33.

Siegert, I., Banks, C., 2005. The effect of volatile fatty acid additions on the anaerobic digestion of cellulose and glucose in batch reactor. Process Biochemistry 40, 3412-3418.

Sun, Y., Li, Y.-L, Bai, S., Hu, Z.-D., 1999. Modeling and simulation of an in situ product removal process for lactic acid production in an airlift bioreactor. Industrial and Engineering Chemistry Research 38(9), 3290-3295.

Ten Brummeler, E., Horbach, H. C. J. M., Koster, I. W., 1991. Dry anaerobic batch digestion of the organic fraction of municipal solid waste, Journal of Chemical Technology and Biotechnology 50, 191-209.

Veeken, A., Hamelers, B., 1999. Effect of temperature on hydrolysis rates of selected biowaste components. Bioresource Technology 69, 249-254.

Veeken, A. H. M., Hamelers, B. V. M., 2000. Effect of substrate seed mixing and leachate recirculation on solid state digestion of biowaste. Water Science and Technology 41 (3), 255-262.

Wang, G., Wang, D. I. C., 1984. Elucidation of growth inhibition and acetic production by Clostridium thermoaceticum. Applied and Environmental Microbiology 47 (2), 294-298.

Weast R.C. (ed.), 1981. Handbook of Chemistry and Physics. CRC Press Inc. Boca Raton, 
Florida, USA, p. D-145.

Zheng, X. J., Yu, H.Q., 2005. Inhibitory effects of butyrate on biological hydrogen production with mixed anaerobic cultures. Journal of Environmental Management 74, 65-70. 


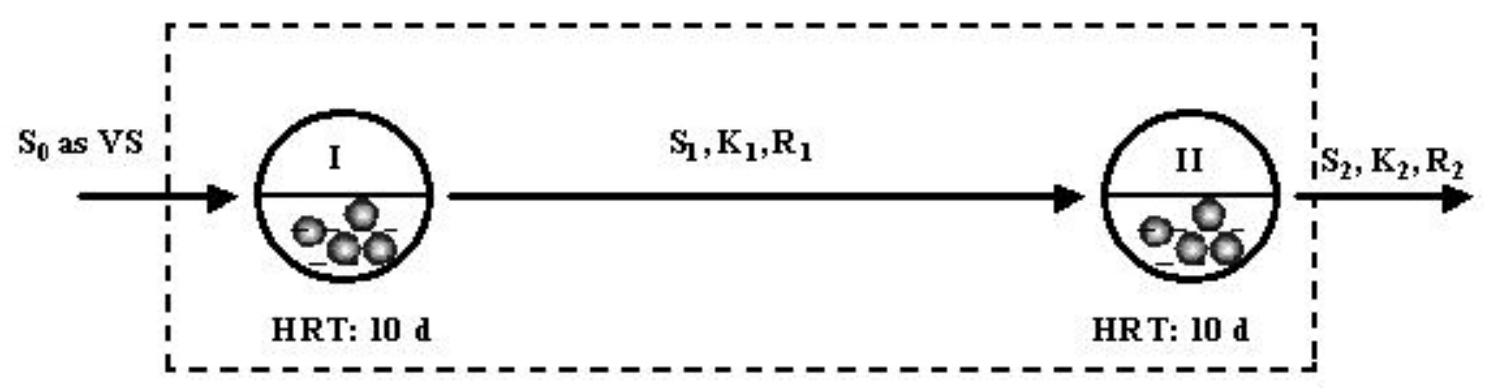

Cascade Process 1: appare nt HRT: $20 \mathrm{~d}$

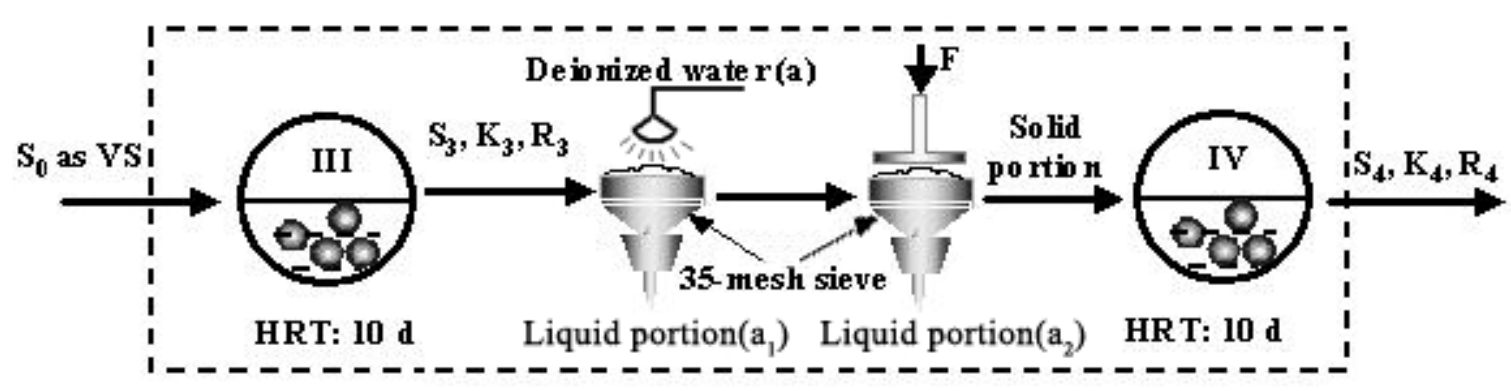

Cascade Process 2: appare nt HRT: 20 d

Fig. 1. Process configurations of the continuous experiment. a (g): the weight of the deionized water added daily, $50 \mathrm{~g}$; $\mathrm{a}_{1}$ (g): the weight of the liquid leached when flushing; $a_{2}$ (g): the weight of the liquid leached by juice presser, $a_{1}+a_{2}=50 g ; S$ (g-VS/L): VS concentration in each stream; $K$ (/d): the hydrolysis rate constant of each fermenter; R: the VA increasing ratios; $P$ : juice presser. 


\section{Table 1}

\section{Conditions of the continuous experiment}

\begin{tabular}{ccccc}
\hline Process & Fermenter No. & HRT (day) & Feeding rate (/d) & Loading rate (/L/d) \\
\hline \multirow{2}{*}{ CP1 } & I & 10 & 180 g fresh soybean meal & 100 g soybean meal \\
& II & 10 & 180 g sludge from fermenter I & 100 sludge from fermenter I \\
& III & 10 & 180 g fresh soybean meal & $(180 \mathrm{~g}$ sludge from fermenter III +50 g deionized water \\
CP2 & IV & 10 & $180 \mathrm{~g}$ sludge from fermenter III +50 g deionized water & -50 g liquid leached by flushing and pressing) $/ 1.8$ \\
\hline
\end{tabular}




\section{Table 2}

Final parameters for all fermenters in the batch experiment

\begin{tabular}{|c|c|c|c|c|c|c|c|c|c|c|c|}
\hline \multirow{2}{*}{$\begin{array}{c}\text { Fermenter } \\
\text { No. }\end{array}$} & \multirow[b]{2}{*}{$\mathrm{pH}(-)$} & \multirow[b]{2}{*}{ TVA(g/L) } & \multirow{2}{*}{$\begin{array}{c}\mathrm{VA} \\
\text { increasing } \\
\text { ratio }\left(R_{V A}\right)\end{array}$} & \multicolumn{2}{|c|}{ VA distribution } & \multirow[b]{2}{*}{ U-VA(g/L) } & \multicolumn{5}{|c|}{ VA spectrum } \\
\hline & & & & $\begin{array}{l}\text { I-VA } \\
(\%)\end{array}$ & $\begin{array}{c}\text { U-VA } \\
(\%)\end{array}$ & & $\begin{array}{c}\text { formic } \\
\text { acid (\%) }\end{array}$ & $\begin{array}{c}\text { acetic } \\
\text { acid (\%) }\end{array}$ & $\begin{array}{l}\text { propionic } \\
\text { acid (\%) }\end{array}$ & $\begin{array}{l}\text { succinic } \\
\text { acid (\%) }\end{array}$ & $\begin{array}{c}\text { malic } \\
\text { acid (\%) }\end{array}$ \\
\hline $\mathrm{I}$ & $5.1 \pm 0.1$ & $17.3 \pm 3.3$ & $33.6 \pm 6.5$ & $68.5 \pm 0.1$ & $31.5 \pm 0.1$ & $5.3 \pm 0.2$ & $8.4 \pm 3.5$ & $50.9 \pm 2.5$ & $40.2 \pm 5.3$ & $0.6 \pm 0.6$ & ND \\
\hline II & $4.6 \pm 0.1$ & $14.3 \pm 0.7$ & $0.4 \pm 0.1$ & $39.0 \pm 0.1$ & $61.0 \pm 0.1$ & $8.7 \pm 0.6$ & $4.5 \pm 0.6$ & $81.0 \pm 17.1$ & $9.6 \pm 13.6$ & $4.9 \pm 4.2$ & ND \\
\hline III & $4.5 \pm 0.1$ & $20.0 \pm 1.9$ & 0 & $32.9 \pm 0.1$ & $67.1 \pm 0.1$ & $13.3 \pm 0.0$ & $0.4 \pm 0.4$ & $95.9 \pm 0.5$ & ND & $2.2 \pm 3.1$ & $1.6 \pm 2.2$ \\
\hline IV & $4.2 \pm 0.2$ & $25.7 \pm 1.4$ & 0 & $19.2 \pm 0.1$ & $80.8 \pm 0.1$ & $20.7 \pm 0.9$ & $1.0 \pm 1.4$ & $98.5 \pm 0.9$ & ND & $0.5 \pm 0.6$ & ND \\
\hline
\end{tabular}

Note: ND represents undetectable. 
Table 3

Analysis of VA for all fermenters in the continuous experiment

\begin{tabular}{|c|c|c|c|c|c|c|c|c|c|c|c|c|c|}
\hline \multirow{2}{*}{\multicolumn{2}{|c|}{$\begin{array}{c}\text { fermenter } \\
\text { No. }\end{array}$}} & \multicolumn{2}{|c|}{$\mathrm{pH}(-)$} & \multicolumn{2}{|c|}{ TVA (g/L) } & \multirow{2}{*}{$\begin{array}{c}\mathrm{VA} \\
\text { Increasing } \\
\text { ratio }\left(\mathrm{R}_{\mathrm{VA}}\right) \\
\end{array}$} & \multirow{2}{*}{$\begin{array}{c}\text { VA } \\
\text { contribution } \\
(\%) \\
\end{array}$} & \multicolumn{2}{|c|}{ VA distribution (\%) } & \multicolumn{4}{|c|}{ VA spectrum } \\
\hline & & in & out & in & out & & & I-VA (\%) & U-VA (\%) & $\begin{array}{l}\text { formic } \\
\text { acid (\%) }\end{array}$ & $\begin{array}{c}\text { acetic } \\
\text { acid (\%) }\end{array}$ & $\begin{array}{c}\text { propionic } \\
\text { acid (\%) }\end{array}$ & $\begin{array}{l}\text { succinic } \\
\text { acid (\%) }\end{array}$ \\
\hline \multirow[t]{2}{*}{ CP1 } & I & $6.3 \pm 0.2$ & $5.4 \pm 0.0$ & & $8.1 \pm 0.1$ & & 72.3 & $82.7 \pm 0.0$ & $17.3 \pm 0.0$ & $0.6 \pm 0.0$ & $79.3 \pm 0.2$ & $10.1 \pm 0.0$ & $10.1 \pm 0.2$ \\
\hline & II & $5.4 \pm 0.0$ & $5.0 \pm 0.2$ & $8.1 \pm 0.1$ & $11.2 \pm 0.3$ & 0.4 & 27.7 & $65.5 \pm 0.0$ & $34.5 \pm 0.1$ & $0.7 \pm 0.0$ & $78.4 \pm 0.1$ & $10.7 \pm 0.1$ & $10.3 \pm 0.0$ \\
\hline \multirow[t]{2}{*}{ CP2 } & III & $6.3 \pm 0.2$ & $5.4 \pm 0.0$ & & $8.1 \pm 0.1$ & & 54.0 & $82.7 \pm 0.0$ & $17.3 \pm 0.0$ & $0.6 \pm 0.0$ & $79.3 \pm 0.1$ & $10.1 \pm 0.1$ & $10.1 \pm 0.1$ \\
\hline & IV & $5.4 \pm 0.0$ & $5.1 \pm 0.2$ & $5.3 \pm 0.2$ & $12.2 \pm 0.5$ & 1.3 & 46.0 & $68.4 \pm 0.0$ & $31.6 \pm 0.1$ & $0.8 \pm 0.0$ & $80.2 \pm 0.3$ & $9.4 \pm 0.0$ & $9.6 \pm 0.0$ \\
\hline
\end{tabular}


Table 4

Steady-state parameters for all fermenters in the continuous experiment

\begin{tabular}{|c|c|c|c|c|c|c|}
\hline \multirow{2}{*}{\multicolumn{2}{|c|}{ Fermenter No. }} & \multicolumn{2}{|c|}{ VS (g/L) } & \multirow{3}{*}{$\frac{\text { VS gradient }(\mathrm{g} / \mathrm{L})}{16}$} & \multirow{3}{*}{$\begin{array}{c}\text { VS degradation ratio (R, \%) } \\
7.6\end{array}$} & \multirow{3}{*}{$\begin{array}{c}\text { Hydrolysis rate constant }\left(\mathrm{K}_{\mathrm{h}}, 10^{-3} / \mathrm{d}\right) \\
7.9\end{array}$} \\
\hline & & \multirow{2}{*}{$\frac{\text { in }}{210 \pm 1.8}$} & \multirow{2}{*}{$\begin{array}{c}\text { out } \\
194 \pm 0.3\end{array}$} & & & \\
\hline CP1 & I & & & & & \\
\hline & II & $194 \pm 0.3$ & $175 \pm 1.2$ & 19 & 9.8 & 10.2 \\
\hline \multirow[t]{2}{*}{$\mathrm{CP} 2$} & III & $210 \pm 1.8$ & $194 \pm 0.3$ & 16 & 7.6 & 7.9 \\
\hline & IV & $192 \pm 0.9$ & $160 \pm 1.9$ & 32 & 16.7 & 18.2 \\
\hline
\end{tabular}

